\title{
Phylogenetic analysis identifies the invertebrate pathogen Helicosporidium sp. as a green alga (Chlorophyta)
}

\author{
1 Department of \\ Entomology and \\ Nematology, University of \\ Florida, Gainesville, \\ FL 32611, USA \\ 2 Center for Medical, \\ Agricultural and \\ Veterinary Entomology, \\ USDA, ARS, Gainesville, \\ FL 32604, USA
}

\author{
Aurélien Tartar, ${ }^{1}$ Drion G. Boucias, ${ }^{1}$ Byron J. Adams ${ }^{1}$ and James J. Becnel ${ }^{2}$ \\ Author for correspondence: Aurélien Tartar. Tel: +1 3523921901 ext. 202. Fax: +1 3523920190. \\ e-mail: aurelien@ufl.edu
}

\begin{abstract}
Historically, the invertebrate pathogens of the genus Helicosporidium were considered to be either protozoa or fungi, but the taxonomic position of this group has not been considered since 1931. Recently, a Helicosporidium sp., isolated from the blackfly Simulium jonesi Stone \& Snoddy (Diptera: Simuliidae), has been amplified in the heterologous host Helicoverpa zea. Genomic DNA has been extracted from gradient-purified cysts. The 18S, 285 and 5.8S regions of the Helicosporidium rDNA, as well as partial sequences of the actin and $\beta$-tubulin genes, were amplified by PCR and sequenced. Comparative analysis of these nucleotide sequences was performed using neighbour-joining and maximum-parsimony methods. All inferred phylogenetic trees placed Helicosporidium sp. among the green algae (Chlorophyta), and this association was supported by bootstrap and parsimony jackknife values. Phylogenetic analysis focused on the green algae depicted Helicosporidium sp. as a close relative of Prototheca wickerhamii and Prototheca zopfii (Chlorophyta, Trebouxiophyceae), two achlorophylous, pathogenic green algae. On the basis of this phylogenetic analysis, Helicosporidium sp. is clearly neither a protist nor a fungus, but appears to be the first described algal invertebrate pathogen. These conclusions lead us to propose the transfer of the genus Helicosporidium to Chlorophyta, Trebouxiophyceae.
\end{abstract}

Keywords: Helicosporidium, phylogeny, invertebrate pathogen, entomopathogen, green algae

\section{INTRODUCTION}

The Helicosporidia are a unique group of pathogens found in diverse invertebrate hosts. Members of this group are characterized by the formation of a cyst stage that contains a core of three ovoid cells and a single filamentous cell (Fig. 1) (Kellen \& Lindegren, 1974; Lindegren \& Hoffman, 1976). The group is very poorly known and its taxonomic position has remained incertae sedis. This pathogen, initially detected in a

Abbreviations: LSU, large subunit; NJ, neighbour-joining; SSU, small subunit.

The GenBank accession numbers for the sequences of the $18 \mathrm{~S}, 28 \mathrm{~S}$ and ITS1-5.8S-ITS2 regions of the rDNA and the actin and $\beta$-tubulin genes of Helicosporidium sp. are respectively AF317893, AF317894, AF317895, AF317896 and AF317897. ceratopogonid (Diptera), was described and named Helicosporidium parasiticum by Keilin (1921) and was placed in a separate order, Helicosporidia, within Cnidiospora (Protozoa) by Kudo (1931). Since then, additional helicosporidians have been detected in mites, cladocerans, trematodes, collembolans, scarabs, mosquitoes, simuliids and pond-water samples (Kellen \& Lindegren, 1973; Fukuda et al., 1976; Sayre \& Clark, 1978; Purrini, 1984; Avery \& Undeen, 1987). Weiser $(1964,1970)$ examined the type material and a new isolate of Helicosporidia from a hepialid larva and proposed that this organism should be transferred to the Ascomycetes, because of some analogies in pathways of infection. Additionally, Kellen \& Lindegren (1974) isolated a Helicosporidium from infected larvae and adults of Carpophilus mutilatus (Coleoptera: Nitidulidae) and described its life cycle in a lepidopteran host, the navel orangeworm, Paramyelois 


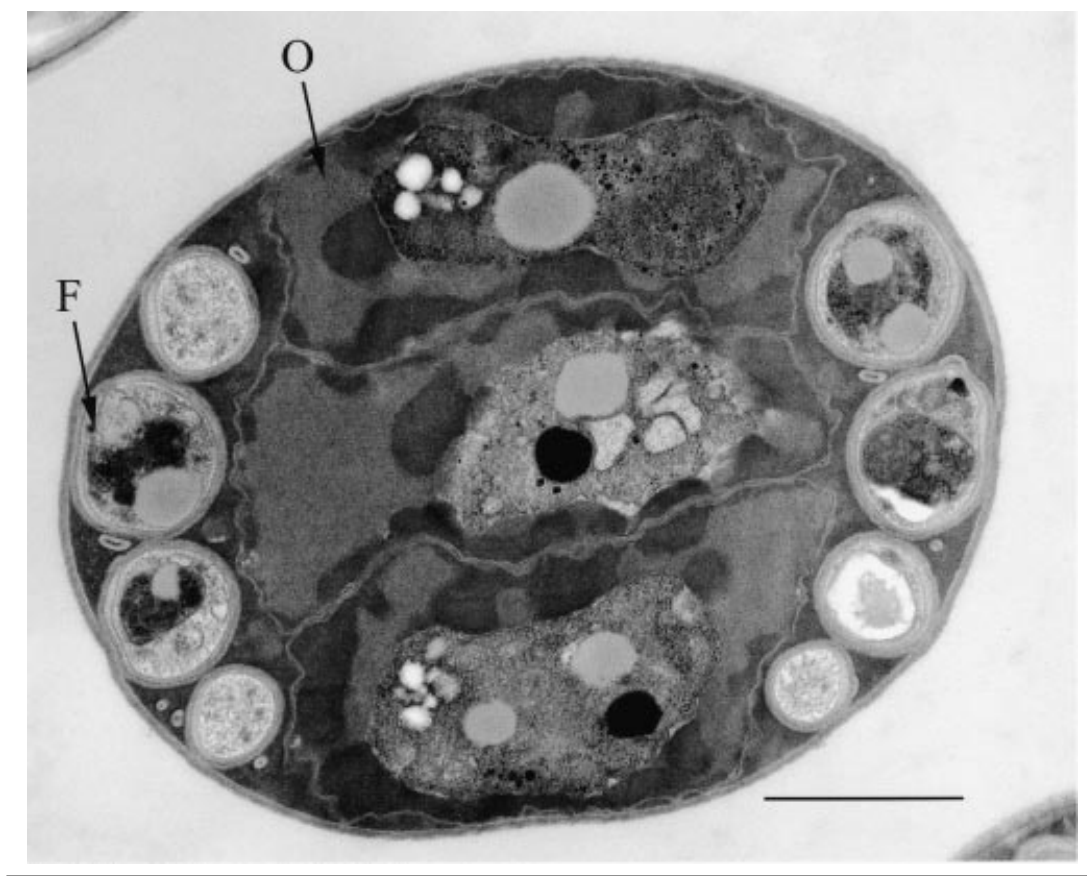

Fig. 1. Transmission electron micrograph of a cyst of the Helicosporidium sp. from Simulium jonesi. The mature cyst is composed of three central ovoid cells $(\mathrm{O})$ and the peripherally located filamentous cell (F) contained within a multilayered cyst wall. Bar, $1 \mu \mathrm{m}$.

transitella. They agreed that this organism is not a protozoan but remained uncertain about its taxonomic position. Later, Lindegren \& Hoffman (1976) proposed that the developmental stages of this organism placed it closer to the Protozoa than to the Fungi. Because of this uncertain taxonomic status, the Helicosporidia have not appeared in classification systems of either the Protozoa or the Fungi (Cavalier-Smith, 1998; Tehler et al., 2000).

Recently, a Helicosporidium sp. isolated from the blackfly Simulium jonesi Stone \& Snoddy (Diptera: Simuliidae) has been shown to replicate in a heterologous host, Helicoverpa zea (Lepidoptera: Noctuidae), which provided a means to produce quantities sufficient for density-gradient extraction of the infectious cyst stage (Boucias et al., 2001). In order to evaluate the taxonomic position of this Helicosporidium sp. within the eukaryotic tree, we extracted genomic DNA from the cyst preparation and amplified several targeted genes $(5.8 \mathrm{~S}, 28 \mathrm{~S}$ and $18 \mathrm{~S}$ rRNA regions and partial sequences of the actin and $\beta$ tubulin genes) by PCR. These genes were selected because they have been used extensively to infer deep eukaryotic phylogenies (Philippe \& Adoutte, 1998). Amplified genes were sequenced and information from nucleotide sequences was subjected to comparative analysis.

\section{METHODS}

Cyst preparation and DNA extraction. Helicosporidium sp. was isolated originally from the blackfly Simulium jonesi Stone \& Snoddy (Diptera: Simuliidae) and produced in Helicoverpa zea. Approximately $4 \times 10^{7}$ cysts suspended in $0.15 \mathrm{M} \mathrm{NaCl}$ were applied to a linear gradient of 1.00
$1.3003 \mathrm{~g}$ Ludox HS40 $\mathrm{ml}^{-1}$ (DuPont). Helicosporidial cysts that banded at an estimated density of $1.17 \mathrm{~g} \mathrm{ml}^{-1}$ were collected, diluted in 10 vols deionized water and washed free of residual Ludox by repeated low-speed centrifugation steps. The pellet, resuspended in $50 \mu$ water, was extracted with the use of the Masterpure Yeast DNA extraction kit (Epicentre Technologies), following the manufacturer's protocol. Examination of the cells before and after lysis treatment revealed the presence of numerous, highly refractile cysts before treatment and, after incubation in the lysis buffer at $50{ }^{\circ} \mathrm{C}$, cysts appeared to dehisce, releasing the filamentous cells. However, no massive disruption of the ovoid cells or filamentous cells was observed in these preparations. Visible pellets were observed after RNase treatment, phenol/chloroform extraction and ethanol precipitation. The final pellet, suspended in molecular-biologygrade water, was frozen at $-20^{\circ} \mathrm{C}$. The DNA preparations, electrophoresed on a $0.8 \%$ agarose gel and stained with ethidium bromide, produced a single, discrete $\sim 20 \mathrm{~kb}$ band diagnostic for genomic DNA.

Mature cysts were also processed for electron microscopy according to previously published protocols (Boucias et al., 2001).

Amplification, cloning and sequencing of extracted DNA. The ITS1-5.8S-ITS2, 28S and $18 \mathrm{~S}$ ribosomal regions of the helicosporidial DNA were amplified with a mixture of $T a q$ DNA polymerase (Promega) and $P f u$ polymerase (Stratagene), using the primers TW81 and AB28 for the ITS-5.8S (Curran et al., 1994) and NL-1 and NL-4 primers for the 28S (Kurtzman \& Robnett, 1997). Two primer sets, designed from consensus regions of selected fungal, algal and protozoan sequences downloaded from GenBank, were used to amplify the $18 \mathrm{~S}$ region. Several series of primers, also designed from consensus regions of selected fungal, algal and protozoan genes, were used to amplify partial sequences of the actin and $\beta$-tubulin genes by PCR. DNA was excised from agarose gels, extracted with the QiaxII gel extraction 
kit (Qiagen) and sent to the Interdisciplinary Center for Biotechnology Research (ICBR) at the University of Florida for sequencing.

DNA sequence analysis. The helicosporidial $18 \mathrm{~S}$ rDNA region sequence was aligned with 138 other sequences from representative eukaryotic taxa obtained from the Ribosomal Database Project (RDP; Maidak et al., 2000). Downloaded sequences were pre-aligned based on the secondary structure of the rDNA. An additional 18S sequence from the pathogenic alga Prototheca wickerhamii was downloaded from GenBank (accession no. X56099) and incorporated in the small-subunit (SSU) RNA dataset. Additionally, 28S sequences were downloaded from GenBank and aligned with the helicosporidial 28S sequence using CLUSTAL $\mathrm{X}$ (Thompson et al., 1997). Eventually, the SSU- and large subunit (LSU)-rDNA datasets were combined to infer one single ribosomal phylogeny. Both actin and $\beta$-tubulin sequences were aligned with homologous sequences downloaded from GenBank. Alignments were obtained using CLUSTAL X software with default parameters. All datasets were checked by eye before further analyses and are available upon request. They can also be obtained from TreeBase (Morell, 1996; http://www.herbaria.harvard.edu/treebase) with the study accession number S604. The 18S algal alignment was kindly provided by V. A. R. Huss (University of Erlangen, Germany).

Aligned datasets were subjected to a partition-homogeneity test using the program PAUP*, version 4.0b4a (Swofford, 2000), in order to assess the extent of character incongruence between the datasets (Farris et al., 1994). Phylogenies were then reconstructed using neighbour-joining $(\mathrm{NJ})$ as implemented in the PAUP* program version 4.0b4a. NJ analyses were based on the Paralinear/LogDet model of nucleotide substitution (Lockhart et al., 1994). This method allows for non-stationary changes in base composition and has been shown to reduce support for spurious resolutions, such as long-branch attraction. Monophyly of groups was assessed with the bootstrap method (100 replicates). Additionally, maximum-parsimony analyses, including jackknifing (100000 replicates; Farris et al., 1996), were also performed using PAUP*. We chose the latter, conservative approach for its ability to search rapidly a large amount of tree space and to estimate support for an unambiguously resolved group (Lipscomb et al., 1998).

\section{RESULTS}

Five PCR-amplified gene fragments of the Helicosporidium sp. were sequenced. These sequences corresponded to the 18S rDNA, 28S rDNA, the ITS1-5.8S-ITS2 rDNA region and the actin and $\beta$ tubulin genes and were respectively $1558,661,844,880$ and 879 bases in length. All sequences, when examined by BLAST analysis (Altschul et al., 1997), produced matches with extremely low expect (E) values. Sequences from two algal species, Chlamydomonas reinhardtii and Volvox carteri, were highly similar to all five sequences. Additionally, sequences from other algal genera, such as Trebouxia, Scenedesmus or Chlorella, were found to match recurrently with the helicosporidial sequences.

A preliminary partition-homogeneity test showed that the $18 \mathrm{~S}, 28 \mathrm{~S}$ and $5.8 \mathrm{~S}$ sequences were highly con-

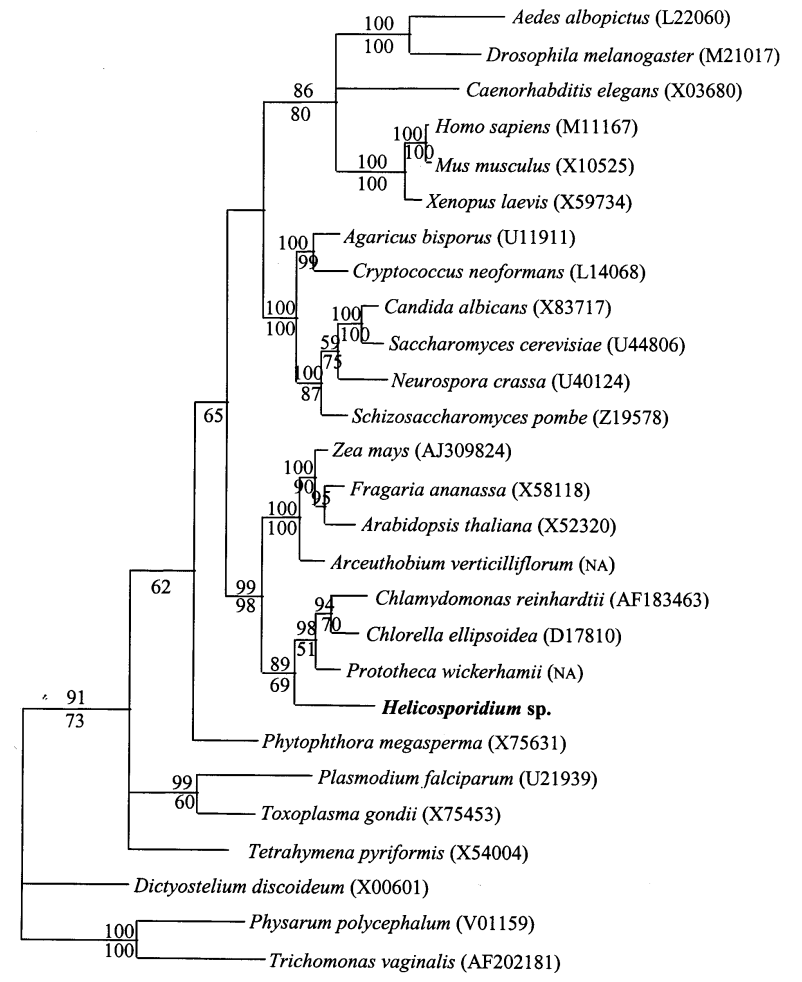

Fig. 2. Phylogram inferred from combined SSU-rDNA and LSU-rDNA nucleotide sequence alignment, showing that Helicosporidium sp. is grouped with the green algae. Numbers above nodes represent the results of bootstrap analyses (100 replicates) using the NJ method. Numbers below nodes are results of parsimony jackknife analyses (100000 replicates). Only values greater than $50 \%$ are shown. SSU-rDNA sequences were downloaded from the RDP Web site. LSU-rDNA sequences were downloaded from GenBank. Accession numbers for these sequences are indicated after each species name. NA, LSU rDNA sequence not available in GenBank.

cordant (data not shown). A first phylogenetic tree was inferred from the $18 \mathrm{~S}$ sequence aligned with the 140 sequences downloaded from the RDP Web site. This tree placed Helicosporidium sp. as a member of the green algae, and this association was supported by significant bootstrap values (data not shown). The tree presented in Fig. 2 was inferred from a combined SSU + LSU rDNA dataset and is concordant with the preliminary result. This tree was rooted by using Dictyostelium discoideum as an outgroup (Fig. 2). Although the taxonomic position of $D$. discoideum is subject to debate (Baldauf et al., 2000), it appears basal in conservative rDNA reconstruction (Lipscomb et al., 1998). Our tree is fairly consistent with other previous molecular phylogenetic studies of eukaryotes (Drouin et al., 1995; Lipscomb et al., 1998; Baldauf et al., 2000), showing that the animal and fungal lineages share a more recent common ancestor than either does with the plant lineage (Baldauf \& Palmer, 1993) and that green algae and green plants form a monophyletic group. Due in part to limited sampling, the relationships between protists are not well resolved, 


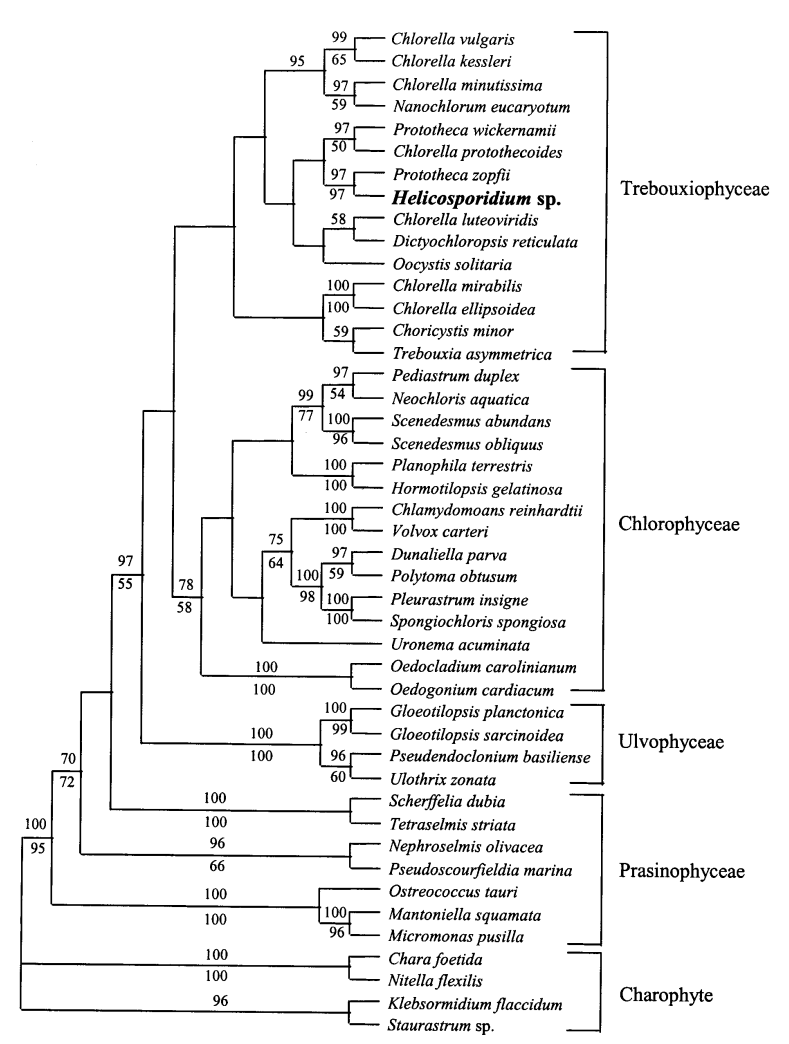

Fig. 3. SSU-rDNA phylogeny of the Chlorophyte green algae. Helicosporidium sp. appears as a member of the class Trebouxiophyceae, as a sister taxon to $P$. zopfii. Numbers above nodes represent the results of bootstrap analyses (100 replicates) using the $\mathrm{NJ}$ method. Numbers below nodes are results of jackknife analyses (100000 replicates) using the maximum-parsimony method. Only values greater than $50 \%$ are shown. The tree is rooted with the Charophyte green algae.

but they all appear near the root of the tree. Importantly, the tree shows that Helicosporidium sp. clusters with the green algae (Chlorophyta), and this relationship is supported by both $\mathrm{NJ}(89 \%)$ and maximum-parsimony $(69 \%)$ bootstrap/jackknife methods (Fig. 2).

The tree presented in Fig. 3 was inferred from an algal SSU-rDNA alignment and addresses the position of Helicosporidium sp. within the Chlorophyta. This tree is rooted with the branch leading to Charophyte algae and shows the four classes of Chlorophyta. As shown previously by Bhattacharya \& Medlin (1998), the class Prasinophyceae is paraphyletic, whereas Ulvophyceae, Trebouxiophyceae and Chlorophyceae are monophyletic. In this tree, Helicosporidium sp. is depicted as a sister taxon to Prototheca zopfii (Trebouxiophyceae) by both distance and parsimony analyses (Fig. 3).

Preliminary alignments showed that neither the actin nor $\beta$-tubulin gene amplified from helicosporidial DNA possessed any introns. As a result, these sequences were aligned with homologous coding sequences (cDNA) downloaded from GenBank. The

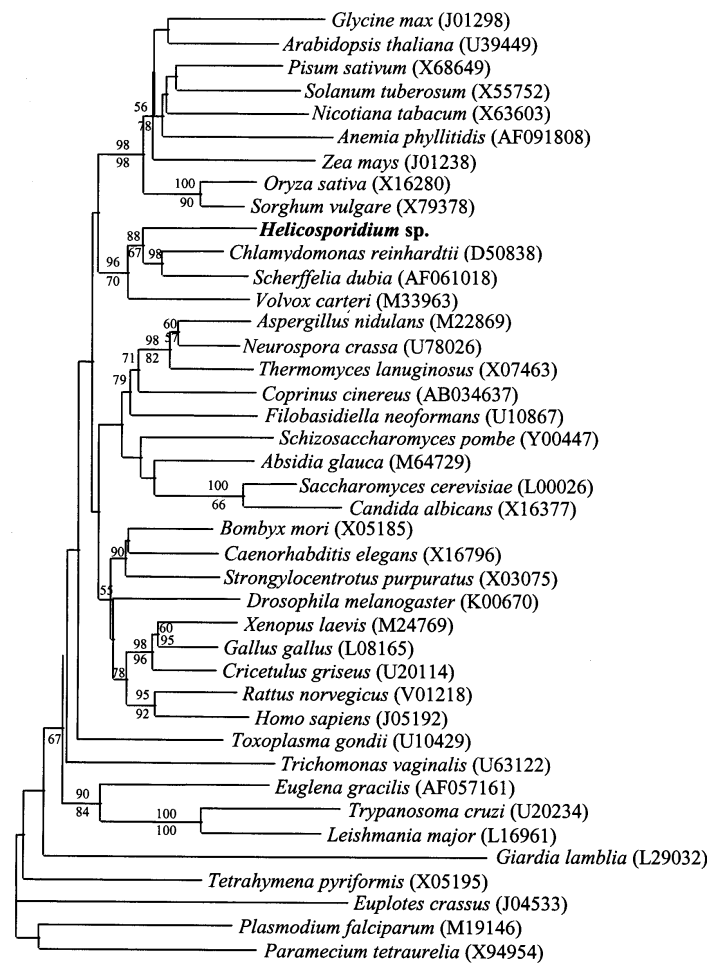

Fig. 4. Phylogenetic tree based on actin gene nucleotide sequences. The tree depicts Helicosporidium sp. as a member of the Chlorophyta. Numbers above nodes represent the results of bootstrap analyses (100 replicates) using the NJ method. Numbers below nodes are the results of jackknife analyses (100000 replicates) using the maximum-parsimony method. Only values greater than $50 \%$ are shown. All but the helicosporidial sequence were downloaded from GenBank. Accession numbers for these sequences are indicated after the name of each species.

phylogenetic trees inferred from the analysis of actin and $\beta$-tubulin fragments are presented in Figs 4 and 5, respectively. The two trees are very similar: they are rooted with the branch leading to the ciliate Euplotes crassus and present branching patterns common to most eukaryotic phylogenies. All protists are clustered near the root of the trees and Metazoa, Fungi and Viridiplantae are all shown to be monophyletic. Both trees confirm that Helicosporidium sp. belongs to the green algae clade, even if the resolution within this clade is not very high. Once again, the nodes linking Helicosporidium $\mathrm{sp}$. to the green algae are all supported, except for the parsimony jackknife of the $\beta$-tubulin tree (Fig. 5).

Additionally, further analyses led to the same conclusion, that Helicosporidium sp. groups with the green algae. Notably, realignments of the RDP SSU-rDNA dataset, modification of gap-penalty parameters or utilization of other distance methods available in PAUP* (such as HKY85 or maximum-likelihood distance) had no effect on the final position of Helicosporidium $\mathrm{sp}$. within the eukaryotic tree. 


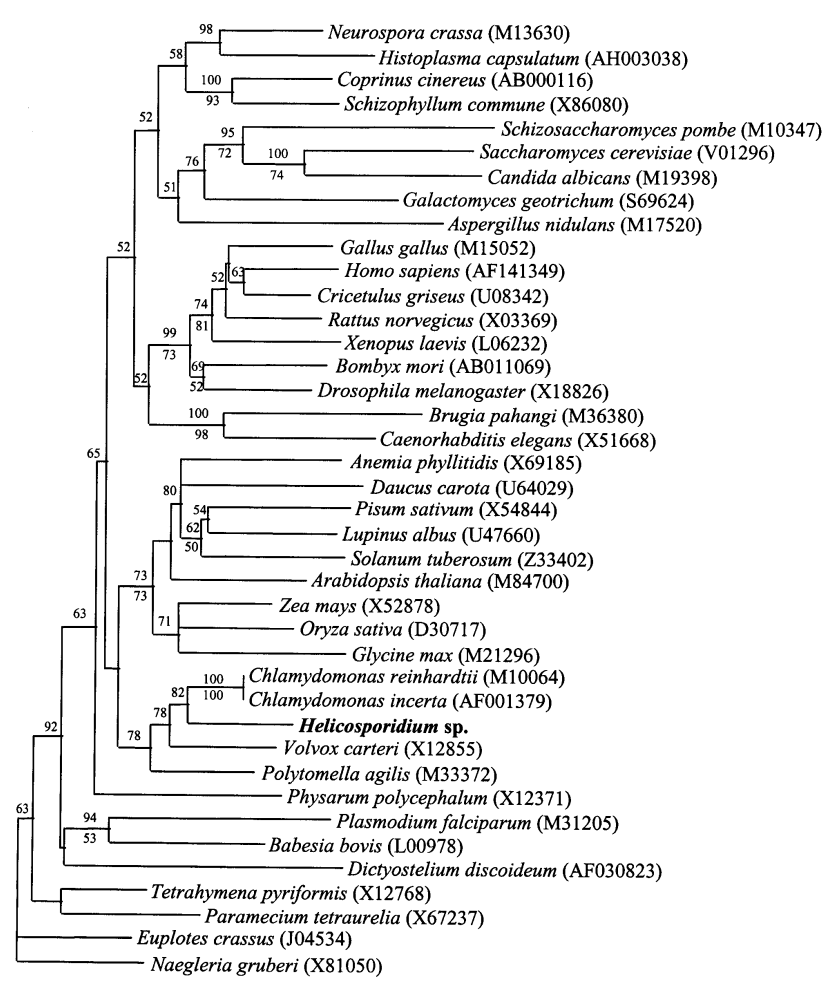

Fig. 5. Phylogenetic tree based on $\beta$-tubulin gene nucleotide sequences. In this tree, Helicosporidium sp. appears as a sister taxon to the genus Chlamydomonas. Numbers above nodes represent the results of bootstrap analyses (100 replicates) using the $\mathrm{NJ}$ method. Numbers below nodes are the results of jackknife analyses (100000 replicates) using the maximumparsimony method. Only values greater than $50 \%$ are shown. All but the helicosporidial sequence were downloaded from GenBank. Accession numbers for these sequences are indicated after the name of each species.

\section{DISCUSSION}

All trees obtained in this phylogenetic study present a fairly reasonable branching pattern, with major divisions corresponding to conventional taxonomic classification (Kinetoplastida, Alveolata, Viridiplantae, Fungi and Metazoa). On the basis of these phylogenies, Helicosporidium sp. is clearly unrelated to any group of Protozoa (Philippe \& Adoutte, 1998). This result suggests that the early attempt of Kudo (1931) to classify this organism within the Protozoa may have been wrong, but it is consistent with studies by Weiser (1970) and Kellen \& Lindegren (1974), both of which proposed the removal of the Helicosporidia from the Protozoa. However, in the most recent study of which we are aware, Lindegren \& Hoffman (1976) refused this suggestion and reaffirmed that the Helicosporidia have affinities with the Protozoa, based on the presence of well-defined Golgi bodies and mitotic division of the nucleus.

None of our phylogenetic trees depicted this Helicosporidium $\mathrm{sp}$. as a member of the kingdom Protozoa (as defined by Cavalier-Smith, 1993). Instead, they consistently and stably grouped Helicosporidium sp. among members of Chlorophyta, suggesting that this invertebrate pathogen is a green alga. Considering the fact that comparative sequence analysis is a robust method that provides resolving power for clade identification, we think that the appropriate place for Helicosporidium is within the Chlorophyta. Furthermore, an $18 \mathrm{~S}$ rDNA-based phylogeny of the Chlorophyta depicted Helicosporidium sp. as a member of the class Trebouxiophyceae and as a very close relative of the genus Prototheca. Although Helicosporidium sp. always clusters with $P$. zopfii, this is probably due to a long-branch-attraction phenomenon, as Helicosporidium sp. is believed to have a very fast evolutionary clock (V. A. R. Huss, personal communication). The nucleotide sequences are sufficiently different to warrant the conclusion that Helicosporidium represents a separate genus within the Trebouxiophyceae.

It may be argued that our helicosporidial sequences, because they were amplified with universal primers, may be from a potential algal contaminant. However, it should be noted that our Helicosporidium sp. was purified carefully by gradient centrifugation after propagation in Helicoverpa zea. Furthermore, Boucias et al. (2001) also propagated Helicosporidium sp. in vitro and extracted DNA from both in vitro and in vivo sources. An RFLP analysis of the 18S rRNA gene amplified from these two sources produced identical digest patterns, demonstrating the integrity of the extracted helicosporidial genomic DNA used in this study (Boucias et al., 2001). Also, DNA has been extracted from a second strain of Helicosporidium sp. and SSU-rRNA gene sequences from the two strains are highly similar (data not shown).

The association of Helicosporidium sp. with the genus Prototheca is interesting from a biological perspective. Members of both genera are achlorophylous and animal pathogens. To date, Helicosporidium spp. have been identified as invertebrate pathogens, whereas Prototheca spp. are known to be pathogenic to vertebrates, including humans (Galan et al., 1997; Mohabeer et al., 1997). Mohabeer et al. (1997) reported that $P$. wickerhamii, although being primarily skin-infectious, can invade several human tissues, including liver, spleen, small intestine, lymph nodes, central nervous system and blood. P. zopfii is also reported to be a human pathogen (Galan et al., 1997). Morphologically, the vegetative cells of the Helicosporidium sp. produced under in vitro and in vivo conditions are reminiscent of those reported for the genus Prototheca. We noticed that, as protothecans, the vegetative cells of Helicosporidium sp. undergo one or two cell divisions within a pellicle. This pellicle eventually splits open or dehisces, releasing either two or four daughter cells from the parent cell wall or pellicle (Boucias et al., 2001). However, to our knowledge, it has not been reported that protothecans produce a mature cyst containing the filamentous cell, which is the unique morphological feature that charac- 
terizes the genus Helicosporidium (Fig. 1). We are confident in the fact that deeper analysis may provide more precision with regard to the relationship between the genera Helicosporidium and Prototheca. Notably, comparative analysis of mitochondrial genomes has been shown to be a very powerful tool for classification of green algae (Nedelcu et al., 2000). Similarly, observations on ultrastructure and cell biology may provide additional data to confirm our conclusions (Taylor, 1999).

Both morphological and molecular evidence suggest that the appropriate place for the group Helicosporidia is within the green algae. Therefore, we propose that the genus Helicosporidium represents the first reported algal entomopathogen and should be placed among the Chlorophyta, Trebouxiophyceae.

\section{ACKNOWLEDGEMENTS}

The authors thank V. A. R. Huss (University of Erlangen, Germany) for providing the green algal rDNA alignment and S. Shapiro (USDA/ARS/CMAVE, Gainesville, FL, USA) for preparing the transmission electron micrograph. We acknowledge the technical support of C. Stokes and S. White, as well as the ICBR Sequencing Facility at the University of Florida. We thank J. E. Maruniak and M. A. Hoy (University of Florida) for revision of the manuscript. Florida Experiment Station Journal Series no. R-07899.

\section{REFERENCES}

Altschul, S. F., Madden, T. L., Schäffer, A. A., Zhang, J., Zhang, Z., Miller, W. \& Lipman, D. J. (1997). Gapped BLAST and PSI-BLAST: a new generation of protein database search programs. Nucleic Acids Res 25, 3389-3402.

Avery, S. W. \& Undeen, A. H. (1987). Some characteristics of a new isolate of Helicosporidium and its effect upon mosquitoes. J Invertebr Pathol 49, 246-251.

Baldauf, S. L. \& Palmer, J. D. (1993). Animals and fungi are each other's closest relatives: congruent evidence from multiple proteins. Proc Natl Acad Sci US A 90, 11558-11562.

Baldauf, S. L., Roger, A. J., Wenk-Siefert, I. \& Doolittle, W. F. (2000). A kingdom-level phylogeny of eukaryotes based on combined protein data. Science 290, 972-977.

Bhattacharya, D. \& Medlin, L. (1998). Algal phylogeny and the origin of land plants. Plant Physiol 116, 9-15.

Boucias, D. G., Becnel, J. J., White, S. E. \& Bott, M. (2001). In vivo and in vitro development of the protist Helicosporidium sp. $J$ Eukaryot Microbiol 48, 460-470.

Cavalier-Smith, T. (1993). Kingdom Protozoa and its 18 phyla. Microbiol Rev 57, 953-994.

Cavalier-Smith, T. (1998). A revised six-kingdom system of life. Biol Rev Camb Philos Soc 73, 203-266.

Curran, J., Driver, F., Ballard, J. W. O. \& Milner, R. J. (1994). Phylogeny of Metarhizium: analysis of ribosomal DNA sequence data. Mycol Res 98, 547-552.

Drouin, G., Moniz de Sa, M. \& Zucker, M. (1995). The Giarda lamblia actin gene and the phylogeny of eukaryotes. $J \mathrm{Mol}$ Evol 41, 841-849.

Farris, J. S., Källersjö, M., Kluge, A. G. \& Bult, C. (1994). Testing significance of incongruence. Cladistics 10, 315-319.

Farris, J. S., Albert, V. A., Källersjö, M., Lipscomb, D. \& Kluge,
A. G. (1996). Parsimony jackknifing outperforms neighborjoining. Cladistics 12, 99-124.

Fukuda, T., Lindegren, J. E. \& Chapman, H. C. (1976). Helicosporidium sp. A new parasite of mosquitoes. Mosquito News 39 , 514-517.

Galan, F., Garcia-Martos, P., Palomo, M. J., Beltran, M., Gil, J. L. \& Mira, J. (1997). Onychoprotothecosis due to Prototheca wickerhamii. Mycopathologia 137, 75-77.

Keilin, D. (1921). On the life history of Helicosporidium parasiticum n. g. sp., a new species of protist parasite in the larvae of Dashelaea obscura Winn (Diptera: Ceratopogonidae) and in some other arthropods. Parasitology 13, 97-113.

Kellen, W. R. \& Lindegren, J. E. (1973). New host records for Helicosporidium parasiticum. J Invertebr Pathol 22, 296-297.

Kellen, W. R. \& Lindegren, J. E. (1974). Life cycle of Helicosporidium parasiticum in the navel orangeworm, Paramyelois transitella. J Invertebr Pathol 23, 202-208.

Kudo, R. R. (1931). Handbook of Protozoology. Springfield, IL: C. C. Thomas.

Kurtzman, C. P. \& Robnett, C. J. (1997). Identification of clinically important ascomycetous yeasts based on nucleotide divergence in the $5^{\prime}$ end of the large-subunit (26S) ribosomal DNA gene. $J$ Clin Microbiol 35, 1216-1223.

Lindegren, J. E. \& Hoffman, D. F. (1976). Ultrastructure of some developmental stages of Helicosporidium sp. in the navel orangeworm Paramyelois transitella. J Invertebr Pathol 27, 105-113.

Lipscomb, D. L., Farris, J. S., Källersjö, M. \& Tehler, A. (1998). Support, ribosomal sequences and the phylogeny of the eukaryotes. Cladistics 14, 303-338.

Lockhart, P. J., Steel, M. A., Hendy, M. D. \& Penny, D. (1994). Recovering evolutionary trees under a more realistic model of sequence evolution. Mol Biol Evol 11, 605-612.

Maidak, B. L., Cole, J. R., Lilburn, T. G. \& 9 other authors (2000). The RDP (Ribosomal Database Project) continues. Nucleic Acids Res 28, 173-174.

Mohabeer, A. J., Kaplan, P. J., Southern, P. M., Jr \& Gander, R. M. (1997). Algaemia due to Prototheca wickerhamii in a patient with myasthenia gravis. J Clin Microbiol 35, 3305-3307.

Morell, V. (1996). TreeBASE: the roots of phylogeny. Science 273, 569.

Nedelcu, A. M., Lee, R. W., Lemieux, C., Gray, M. W. \& Burger, G. (2000). The complete mitochondrial DNA sequence of Scenedesmus obliquus reflects an intermediate stage in the evolution of the green algal mitochondrial genome. Genome Res 10, 819-831.

Philippe, H. \& Adoutte, A. (1998). The molecular phylogeny of Eukaryota: solid facts and uncertainties. In Evolutionary Relationships among Protozoa, pp. 25-57. Edited by G. H. Coombs, K. Vickerman, M. A. Sleigh \& A. Warren. Dordrecht: Kluwer.

Purrini, K. (1984). Light and electron microscope studies on Helicosporidium sp. parasitizing orbitid mites (Oribatei, Acarini) and collembola (Apterygota: Insecta) in forest soils. J Invertebr Pathol 44, 18-27.

Sayre, R. M. \& Clark, T. B. (1978). Daphinia magna (Cladocera: Chydoroidea). A new host of a Helicosporidium sp. (Protozoa: Helicosporidia). J Invertebr Pathol 31, 260-261.

Swofford, D. L. (2000). PAUP*. Phylogenetic Analysis Using Parsimony (*and Other Methods). Version 4. Sunderland, MA: Sinauer Associates. 
Taylor, F. J. R. (1999). Ultrastructure as a control for protistan molecular phylogeny. Am Nat 154 (Suppl.), S125-S136.

Tehler, A., Farris, J. S., Lipscomb, D. L. \& Källersjö, M. (2000). Phylogenetic analyses of the fungi based on large rDNA data sets. Mycologia 92, 459-474.

Thompson, J. D., Gibson, T. J., Plewniak, F., Jeanmougin, F. \& Higgins, D. G. (1997). The CLUSTAL-X windows interface: flexible strategies for multiple sequence alignment aided by quality analysis tools. Nucleic Acids Res 25, 4876-4882.

Weiser, J. (1964). The taxonomic position of Helicosporidium parasiticum, Keilin 1924. J Protozool 11 (Suppl.), 112.

Weiser, J. (1970). Helicosporidium parasiticum Keilin infection in the caterpillar of a hepialid moth in Argentina. J Protozool 17, 436-440. 